\title{
The Malaysian Graduate Readiness to be employed in IR 4.0
}

\author{
${ }^{1}$ ERNI TANIUS, ${ }^{2}$ DR. KAMISAH SUPIAN, ${ }^{3}$ ROHAIZA MOHAMAD IDARIS \\ ${ }^{1}$ LECTURER, ${ }^{2}$ LECTURER, ${ }^{3}$ LECTURER \\ FACULTY OF BUSINESS AND ACCOUNTING UNIVERSITY SELANGOR \\ SELANGOR, MALAYSIA
}

\begin{abstract}
Industrial Revolution 4.0 (IR4.0) has become the main issue and gain interest nationally and globally. The most affected of IR 4.0 is employment, particularly to the new graduates. The employment opportunity becomes condensed, and the requirement of the job changes dramatically. Hence, this study aimed to investigate the correlation between the new graduate knowledge, skill, technology, and readiness to be employed in IR 4.0. The core factors that contributed to the readiness for employment in $\mathbf{4 . 0}$ are also recognized. This study's participant is 255 students from two universities, one in public and the other from the private university using an online survey. Meanwhile, descriptive statistics, correlation, and multiple regressions use to analyze the important data. The result indicated that technology and soft skills contributed to the readiness to employ in IR 4.0. However, the respondents agreed that they were a deficiency in using technology in their study. Additionally, the readiness was parallel in all of the universities. Finally, the result proposed that university and government as policymakers need to embed the IR 4.0 knowledge, skill, and technology used in the teaching and learning to ensure the graduates ready to enter the labor market.
\end{abstract}

Keywords: Malaysian graduate, Readiness, Employment, IR 4.0

Introduction

Schwab K, (2016), a professor and World Economic Forum's Executive Chairman, defined IR 4.0 is a building on the used electronics \& information technology services to mechanize the construction. It is described by a combination of more than one technologies that can clear the distance between the physical, digital, and biological spheres as they are nearly the same with that clarifications.

Marr B. 2016, said it denotes the blend of cyber-physical systems, the IOT, and the Internet of Systems. It is the indication of smart workshops where machineries are amplified with the web connectivity \& also they are associated to a system that can foresee the complete manufacture chain and make choices on its own.

A study by Nagy, J., Oláh, J., Erdei E., Máté D. Popp J., 2018, claimed Industry 4.0 technologies are crucial for most companies in almost all the sectors. They found out that automation will affect production as well as the company function. They added that most of these technologies affect the organization's entire function; the effect starts with the production, sales, and new product development. The data and information can be shared with suppliers and customer partners.

In Malaysia, the government invested heavily in the research and development and emphasized in IR4.0. Here, the main objective is to restructure the industrial capability and transmute Malaysia's economy from the low-cost industrial country into the high-value competing producer Mottain M. 2019.

\section{Skills in 4IR}

4 I.R. characteristic is digital, first on the consumer, who relishes more communicating and modified involvements by using social Media, analytics, mobile and cloud technologies; Second, enterprise can force us to use the SMAC technologies so that we can enhance the cost of commercial utilities and transform enterprise association for higher production. Finally, on the operations wave, the companies transform their business using AI, robotics, cognitive computing, and the Industrial IoT (Selamat A, 2017).

It leads to gains in effectiveness and production, transportation and announcement costs will drop, logistics and global supply chains will become more productive. The cost of trade will reduce, opening new markets, and driving economic growth (Schwab K, 2016). The critical features in 4IR use of Mobile Devices, Omni-channel Customer Interaction \& Customer, Augmented Reality/Wearable, Cloud Computing, Big Data Analytics, Authentication \&Fraud Detection, Location Detection Technologies, Smart Sensors, Advanced Human Machine Interface, Internet of Things, Cyber-Physical System (Selamat A, 2017).

A report from McKinsey Global Institute, 2018 in figure 1 shows the workforce skill model that listed the jobs that most probably be affected because of the automation. The report divides the work expertise into five different categories as per the following:

Basic cognitive;

Social and emotional;

Physical and manual;

Higher cognitive;

Technological.

The report concluded that physical and manual workers and the job use the basic cognitive skills in the U.S. and Western Europe 
would be reduced. However, increasing the employees' demands higher cognitive, social, emotional or "soft skills" and technology. The report concluded that automation uses in many functions in the organization, such as marketing, complex information processing, and market trends.

Figure 1: McKinsey Global Institute Workforce Skills Model

Automation and Al will accelerate the shift in skills that the workforce needs.

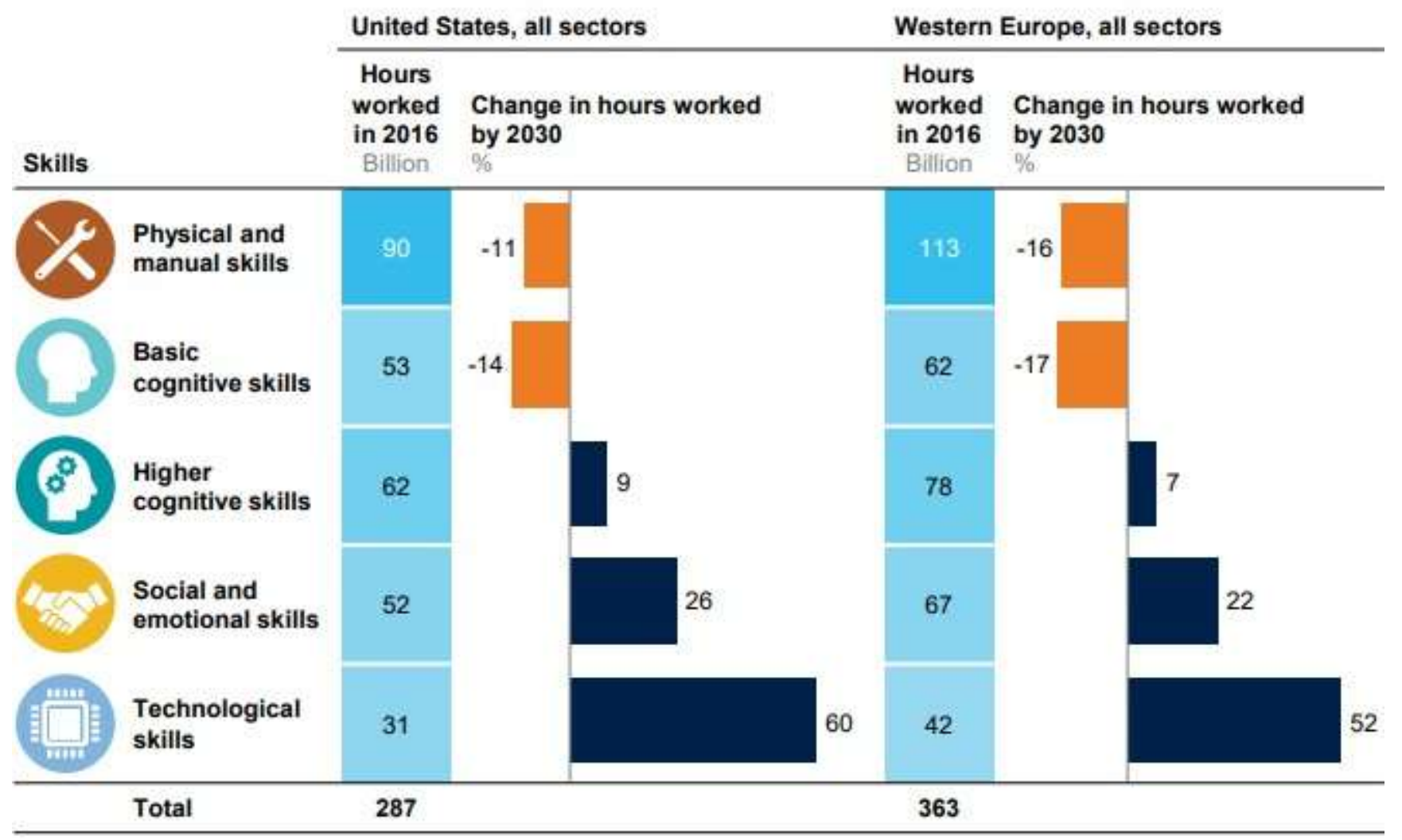

NOTE: Western Europe: Austria, Belgium, Denmark, Finland, France, Germany, Greece, ltaly, Netherlands, Nonway, Spain, Sweden, Switzerland, and the United Kingdom. Numbers may not sum due to rounding.

SOURCE: MoKinsey Global Institute workforce skills model; McKinsey Global Institute analysis

The opportunity of 4IR, as claimed by Schwab K (2016), is to increase effectiveness and production, as transport and announcement expenses will get drip, logistics \& universal supply chains will converted to livelier. The cost of occupation will weaken, and it can surely open the new markets \& it can also drive an economic development. On the contrary, economists Erik Brynjolfsson and Andrew McAfee have pointed out; the revolution could increase greater inequality and potentially disrupt labor markets as automation substitutes for labor across the entire economy result in a net increase in safe and rewarding jobs (in Schwab K, 2016).

\section{Employability in 4IR}

One of the most affected by 4IR is employability, as the hiring requirement is differed that before. The core skills are looking for by industry are; learning services (self-directed learning, cross-discipline, digital skills), thinking skills (creative, resilience, inquisitive, problem solving); and soft skills (ethics, communication) Mustafa Z (2018). In the meantime, Barakat H (2017) alleged lateral thinking and problem-solving competencies, the team works, communicate effectively and improve information technology knowledge as the crucial skills in 4IR. Finally, the World Economic Forum (2016) described three critical interconnected features that affect talent development deployment. First, technology and globalization increase the pace of Destruction, creation of a new job, and skills churn within existing jobs. Second, education and training systems, for now, reported mainly remained static and inadequate for these new needs. Besides, adult training and skilling systems are poorly developed. Third, outdated but dominant cultural norms and institutional create roadblocks, such as gender discrimination.

It expected that the work environment would change in 4IR. Research done by the McKinsey Global Institute found that 
approximately $2 / 3^{\text {rd }}$ of all jobs encompass at least $1 / 3^{\text {rd }}$ of tasks and actions that could be computerized based on present technology. Another $35 \%$ of core skills required by occupations will change or be wholly new in 4IR World Economic Forum, 2017. In IR 4.0, the workforce scenery is active and full of ambiguity. It is increasingly connected with the tech-centered world and demand for non-routine cognitive tasks such as socio-emotional skills (SES) and the interpersonal skills to carry them out (Kattan R.B, 2017).

\section{Student Readiness of Employment in 4IR}

Higher learning institutions are responsible for producing their students ready to enter the labor market. They need to transform, including cyber security, communication, digital competency, programming, entrepreneurship, and marketing Mustafa Z., 2018.

In Malaysia, there is a gap opinion on student or graduate readiness to enter the labor market. Tanius E. 2018 reported that employers and new graduates' perceptions of the primary employability skills urgently required by industry differed. The students claimed that they are ready to enter the workplace market (Tanius E. Susah S. 2015); however, it was denied by the employer. Furthermore, the industry complains that the internship students have a problem with their technical/applied skills (Tanius T., 2015; Erni T., and Che Manisah M.K., 2012). On top of that, they lacked critical/analytical thinking, oral communication, active listening, creativity, and innovation skills (Tanius E, Abdul Rauf R.K., Rosli M.H., and Sharifah Hilmi Syed Abdullah, 2017).

In terms of digital employment readiness, the literature indicates that mainly graduates and young people are not ready yet. Infosys (2016) reported that only those who already have above-average abilities in those skills are interested in upgrading their digital and technological skills. They believe that their education did not prepare them for what to expect from working life. They also said that working with others and communicating effectively are the attributes that make the best employees. Furthermore, they believe that access to new, more flexible, digital tools will enable them to gain new skills far quicker than before. Finally, Mustafa Z (2018) assumed that the industries claimed they ready for technology compensations or ICT employment, but not employees or alumnae found are incapable to work these progressive technologies.

\section{METHODOLOGY}

This study involved private and public university students in Malaysia. A self-administrated questionnaire was used as the method of data collection. A total sample of 251 students had answered the survey. The questionnaire consists of four sections related to factors contributing to their readiness to employ in IR 4.0; they are I: the demographic profile, Section II: socio-economic characteristics of IR 4.0, Section III: technology (knowledge and used), Section IV: skills (knowledge and used), and Section V: Readiness for employment in IR 4.0. The data analysis from this study was carried out using Statistical Package for the Social Sciences (SPSS) software version 16.0. The analysis of the findings was according to the research objectives.

The first step taken in the data analysis was expressive figures, where it provides background information of the respondents connected to the variables being studied. The distribution of respondents is by gender, race, education level, and university. The summaries of frequency and percentage were provided to give a clear view of the respondents' background. Correlation analysis and multiple regressions are used to identify if there is any significant correlation among variables. Finally, a model of students ready to be employed during IR 4.0 is designed. 


\section{RESULT}

Table 1 -Summary of respondent

Demographic Variables

Categories $\quad$ Frequency Percentage

Gender

Male

99

38.82

Female

156

61.17

$18-23$ yrs

90.40

Age

$24-29$ yrs

24

9.60

$30-34$ yrs

0

0.00

35 and above

0

0.00

Diploma

47

18.43

Education level

Degree

Foundation

85

Malay

Race

Chinese

Indian

Others

8

University

Private

199

78.04

Public

56

21.96

Based on the above, the respondents are mainly female (61.17\%), majority or almost all of the age between 18 to 23 years old. In terms of education level, most (48.24\%) degree students with 55.69\% are Malay majority from private universities (78.04\%). The details, as shown in table 1 .

\section{Correlation analysis}

Table 2 Correlation analysis for each variable

\begin{tabular}{lcccc}
\hline Variables & 1 & 2 & 3 & 4 \\
\hline 1. IR 4.0 & - & $0.352^{* *}$ & $0.380^{* *}$ & $0.241^{* *}$ \\
2. KNOWLED.TECHNOLOGY & $0.352^{* *}$ & - & $0.628^{* *}$ & $0.297^{* *}$ \\
3. KNOWLED.SOFT-SKILL & $0.380^{* *}$ & $0.628^{* *}$ & - & $0.239^{* *}$ \\
4. READINESS & $0.241^{* *}$ & $0.297^{* *}$ & $0.239^{* *}$ & - \\
\hline
\end{tabular}

**. Correlation is significant at the 0.01 level (2-tailed).

The table above shows the correlations among the variables. The results show that IR4.0 was consistently associated with higher soft-skill, more frequent positive effect on technology, and less common effect on readiness. Knowledge of technology was positively associated with soft-skill and less effect on readiness. In summary, IR 4.0 over soft-skill and knowledge in technology was found to be a potent predictor on the employment of IR 4.0 


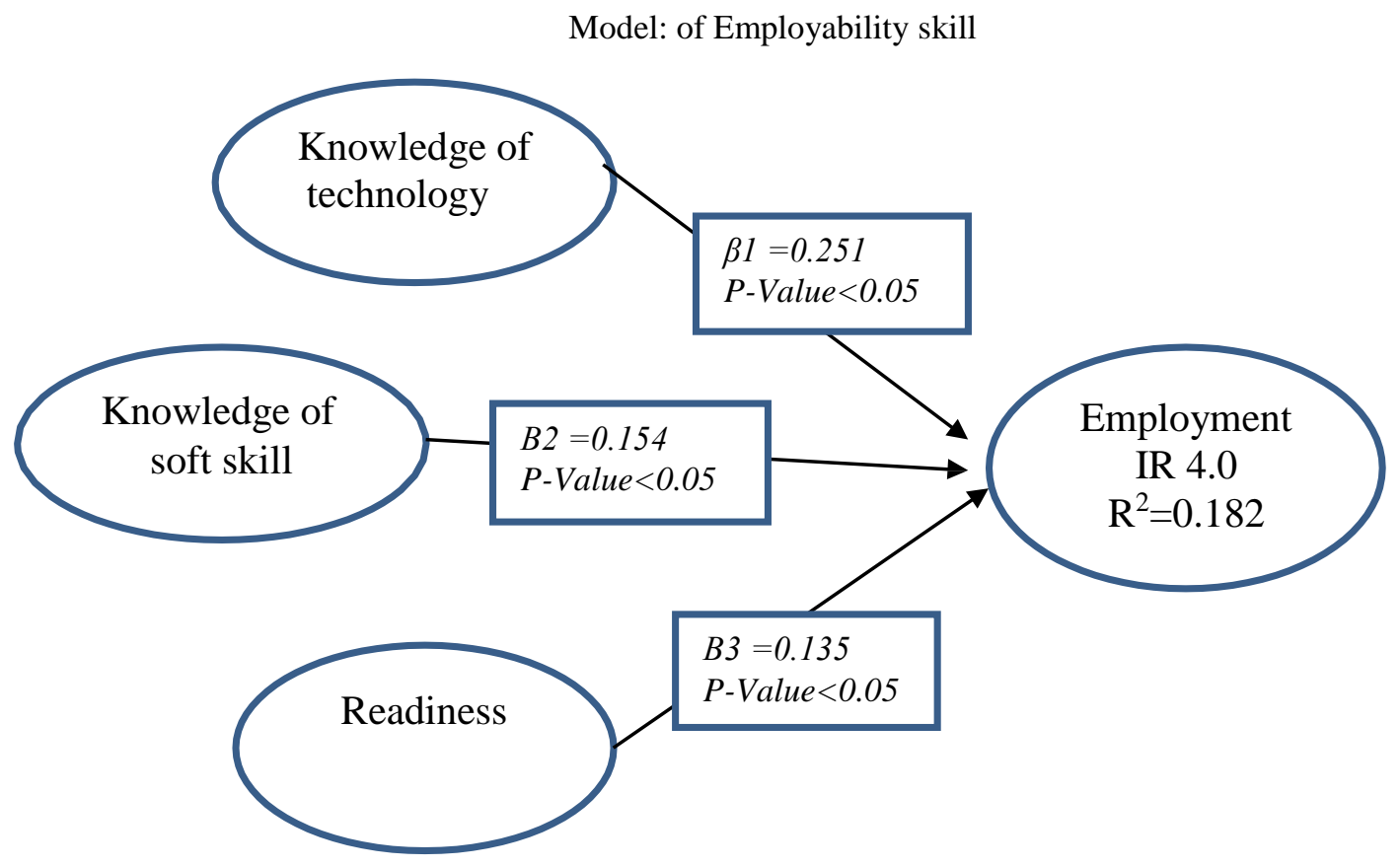

Table 3 Summary statistics, correlations, and results from the regression analysis

\begin{tabular}{lccccc}
\hline Variables & Mean & StD & Correlation & \multicolumn{2}{l}{ Multiple regression weight } \\
& & & & \multicolumn{1}{c}{$\beta$} \\
\hline IR 4.0 & 3.4578 & 0.5525 & & & \\
Knowld. TECH & 3.6173 & 0.6537 & $0.352^{*}$ & $0.213^{*}$ & 0.251 \\
Knowld.SOFT- SKILL & 3.8610 & 0.6525 & $0.380^{*}$ & $0.130^{*}$ & 0.154 \\
& & & & & \\
READINESS & 2.1125 & 0.4733 & $0.241^{*}$ & $0.158^{*}$ & 0.135 \\
\hline
\end{tabular}

*significant at the 0.01 level (2-tailed).

Association and numerous reversion analyses were accompanied to observe the association between the new graduate knowledge, skill, technology, and readiness to be employed in I.R. 4. Table 3 summarizes the correlation and analysis results. As can be seen, each of the variables is positively and significantly connected with the IR 4.0, representative that those with higher scores on these variables tend to have a higher effect on employment of IR 4.0.

The multiple regression model with all three predictors produced $\mathrm{R}^{2}=0.182, \mathrm{~F}(3,251)=18.676$, $\mathrm{p}<.001$. Knowledge on softskill gives a $21.3 \%$ effect on the employment of IR 4.0, while readiness gives a $15.8 \%$ effect, and knowledge on technology gives a $13 \%$ effect on the success of employment IR4.0. However, the results of the analysis show that knowledge in technology give higher effect and significantly predict the successful employment of IR $4.0(\beta 1=0.251 P$-Value $<0.05)$ while readiness shows less effect and significantly predict the successful employment of IR $4.0(B 3=0.135, P$-Value $<0.05)$

\section{Conclusion and limitation}

In summary, soft skills and knowledge in technology were the primary factors of university students being employed in IR 4.0. The study also found that knowledge has the highest effect on the success of employment in IR 4.0. Meanwhile, readiness shows less effect. However, this study has some limitations, such as the study only involved two universities; the study result may not be representative of all the universities in Malaysia.

Additionally, the variable in this study only three; they are characteristics, technology, and soft skill as factors contributing to the university students ready to be employed in IR 4.0. That is the reason why we highly commend future research work to look into holistic trainings, involving more students, and it is also suggested that the employer includes in the future study. Finally, it is recommended that in the future, the factors should be added, such as policy or training, so we will able to identify other factors that may contribute to the student's readiness for employment in I.R.

4.0. However, the current study prominently has determined one model to show the association between students' familiarity on features of IR 4.0, technology, soft skills, and students' readiness in employment in IR 4.0. So, this association could be used as a base work for any of the future study.

Acknowledgments and Greetings: Universiti Selangor - UNISEL, under Bestari Grants 2018 funded this research work. The authors are gratefully thankful to UNISEL and all the members for their support to conduct this study. 


\section{References:}

[1] Barakat, H.,2017, STEM: Bridging Students and 4IR Skills, available in https://www.linkedin.com/pulse/stem-bridgingstudents-4ir-skills-hicham-barakat/ [Accessed 22 June, 2009].

[2] Business Dictionary.com. Available at: http://www.businessdictionary.com/definition/employment.html [Accessed 12 April 2018].

[3] Encyclopedia Britannica, Higher Education, available athttps://www.britannica.com/topic/higher- education, [Accessed 12 April 2018].

[4] Tanius E. 2018, Employability Skills, A Study on the Perception of Business Students Graduate and Employer in Malaysia, Asia Pacific Journal of Research in Business Management, Vol. 9, Issue 1.

[5] Tanius E. and Mohd Kasim C.M., 2012, Enhancing the Effectiveness of Industrial Training and the Relationship with employment Opportunity, Colloquium of Unisel. Research Publications, 2- 3 October 2012, pp. 29

[6] Tanius E. and Susah S. 2015, Employability Skill Readiness among Business' Students, International Journal of Science and Research (IJSR), Volume 4 Issue 8, August 2015 ISSN (Online): 2319-7064

[7] Tanius E, Abdul Rauf R. K., Rosli M. H., and Syed Abdullah S. H. 2017, Competency of Business Students Undergone Industrial Training: Industry Perspectives, Sci.Int. (Lahore),29(5),1163-1168,2017

[8] Grey A. 2016, The 10 skills you need to thrive in the Fourth Industrial Revolution, World Economic Forum, https://www.weforum.org/agenda/2016 [Accessed 10 February 2018]

[9] Infosys 2016, Amplifying Human Potential: Education and Skills for the Fourth Industrial Revolution, available at http://boletines.prisadigital.com. [Accessed 2 February 2018]

[10] Kattan R.B., 2017, Powered by education, East Asia is getting ready for the Fourth Industrial Revolution, The World Bank, available at http://blogs.worldbank.org/education/education-east- Asia-fourth-industrial-revolution. [Accessed 12 April 2018]

[11] Marr B. 2016, Why Everyone Must Get Ready for the 4th Industrial Revolution, Forbes, available in https://www.forbes.com/sites/bernardmarr/2016. [Accessed 12 April 2018]

[12] Mustafa Z. 2018, Producing a highly skilled workforce for the 4IR, New Straits Times Online, available in https://www.nst.com.my/education/2018/01/. [Accessed 10 April 2018]

[13] Schwab K. 2016, The Fourth Industrial Revolution: what it means, how to respond, World Economic Forum, available in https://www.weforum.org/agenda/2016/01. [Accessed 12 March 2018] 